\title{
A VISUALIDADE URBANA CONTEMPORÂNEA COMO CAMPO DE ESTUDOS INTERDISCIPLINARES
}

\author{
Francisco Antônio Zorzo ${ }^{1}$
}

\begin{abstract}
Resumo: O artigo traz uma discussão sobre o estudo da visualidade urbana segundo uma abordagem interdisciplinar. Segundo a proposta aqui indicada, parece útil entender os fenômenos urbanos sob um outro olhar. Torna-se muito conveniente considerar a interação entre tecnologia, arte e ciência na constituição dos estudos sobre o ambiente urbano e sobre a produção da imagen. Tendo em mente tal concepção, pode-se partir de uma referência mais concreta para estudar a cidade e a visualidade, como um campo de múltiplas produções em abordagem interdisciplinar. Para isso foi selecionada a produção do grafite nas metrópoles brasileiras. Nos muros de Salvador há uma série de grafites que merecem a reflexão e um acolhimento crítico por tratarem exatamente de problematizar o olho e o olhar no ambiente da cidade.
\end{abstract}

Palavras-Chave: Cidade, Interdiciplinaridade, Grafite.

\begin{abstract}
This work make a discussion about the study of urban visuality in interdisciplinary aproach. In the research here indicated, near appropriate understand urbans phenomenons at other view. Became very useful to take into consideration the relation between tecnology, art, science in the constituition of the stydies about the environment and the production of the urban image. With this conception, it's possible to start from a concrete reference to observe the city and visuality.To see this problem was selected the case of graffiti in the brasilian metropolis. Graffiti, that are scribbled on the walls of a public place of Salvador, deserve attention and critical reception, because can to render the matter and discussion in direction of the eye and regard into the urban environment.
\end{abstract}

Keywords: Urban study, Intedisciplinary, Graffiti.

1 Professor adjunto da UFBA, lotado no Instituto de Humanidades, Artes e Ciências (IHAC) e integrante do corpo docente do Programa de Pós-graduação em Desenho, Cultura e Interatividade da UEFS. Doutorado e pós-doutorado na Escola Técnica Superior de Arquitetura da Univesidade Politécnica da Catalunha, Barcelona, Espanha. Participa do grupo de pesquisa TR.OPUS da UFBA. Atua na área de conhecimento dos Estudos Urbanos e Ciências Sociais Aplicadas. Endereço eletrônico: fazfeira@uefs.br. 


\section{INTRODUÇÃO}

O estudo da cidade sob o regime da visualidade contemporânea exige que se coloquem algumas questões iniciais: $O$ conhecimento a respeito das cidades, que repousa nos princípios herdados de uma postura puramente disciplinar e racionalista, consegue dar conta da complexidade da cultura urbana? Na vida contemporânea, em que a visualidade toma uma dimensão estratégica, os estudos sobre a produção visual não requerem uma abordagem que leve em conta sua complexidade? Para responder a essa inquietação parece conveniente abrir o leque teórico e articular o conhecimento num campo interdisciplinar.

O objetivo deste estudo é seguir uma linha interdisciplinar para alcançar algumas observações teorizantes (VELLOSO, 2005), visando entender os modos segundo os quais as pessoas interagem e combinam suas vidas cotidianas com a experimentação e o uso espacial da arte, da mídia e da comunicação.

Podem-se utilizar saberes em relação de complementaridade, desde que mantidas as suas diferenças, de modo a constituir um consistente pensar a cidade. Assim é possível captar não apenas as dimensões objetivas e técnicas - urbanísticas, funcionais e instrumentais - do fenômeno urbano, mas também as subjetivas e artísticas. A expressão visual tornou-se uma dimensão estratégica nas sociedades contemporâneas.

Convém reconhecer a visualidade como uma produção que passa pela política, pela técnica e pela estética. Diversos campos de conhecimento ocupam posição privilegiada na discussão de específicos objetos urbanos e visuais, mas não ganham por isso uma exclusividade sobre o campo de conhecimento. Um jogo entre o visível permite que alguns temas, coletivos, agentes e performances gozam de visibilidade pública, e outros não. Aqui leva-se em consideração que visibilidade remete à percepção e capacidade de ver, enquanto que visualidade remete a uma operação visual, a um artificio de construir imagem, seja fotográfica, virtual ou de outro tipo. É esse regime de visualidade que ganha aqui maior peso na análise.

A série que está sendo composta como arte da rua, que aqui vai ser avaliada, é feita por um grupo de artistas que são contemporâneos e que convivem na mesma cidade. Sob diversas condições constroem um olhar, que ultrapassa obviamente o espaço das paredes e das ruas da cidade, proporcionando uma interação simbólica e comunicacional. 
Os artistas da cidade fazem um trabalho de exposição para a coletividade, colocando em discussão o olhar e a visualidade urbana. De um lado eles exibem signos que criam uma estética contemporânea, por outro estabelecem sob forma visual um olhar crítico sobre a cidade. A constatação de que o grafite assim como outras formas da visualidade pode adquirir significados diferentes, que não são univocamente definidos por um ou outro enfoque está ligada ao debate teórico sobre a multiplicidade do sentido (HAMBURGUER, 2007) da realidade.

O projeto de pesquisa que trabalha a cidade e a visualidade, aquí relatado, se volta para a problemática das interações entre realizadores, pesquisadores e espectadores, que não se limita ao espaço urbano e atinge o campo virtual em que o grafite é registrado e torna-se objeto de reflexão. A abordagem interdisciplinar aquí proposta vai na linha do Hamburguer (2007) chama "de disputa pelo controle da produção da representação". Esse enfoque serve para discutir, a partir de amplo material documental, diferentes maneiras de interagir na cidade e problematizar arranjos formais concretos em termos que enfatizem seu caráter de expressão de articulações entre certos sujeitos que procuram, em alguma medida, controlar os mecanismos de construção de uma imagem da cidade.

É muito instigante observar os fenômenos de produção do espaço urbano sob o crivo da resistência e do desejo coletivo. Em meio a um contexto, de caráter mais amplo e de certo modo mais pessimista, em que a construção da cidade cede ao sistema capitalista, esse crivo proporciona um outro olhar sobre a cidade, um olhar criativo que sobrevive às ameaças constantes da homogeneização e da globalização.

Convém aquí situar que, a presente abordagem da constituição dos signos e mensagens da vida da cidade situa o urbano entre os fenômenos políticos e culturais. Pode-se, assim, perceber elementos da contemporaneidade de modo a gerar um conhecimento que capta o fenômeno urbano não apenas nas suas dimensões objetivas e técnicas, mas principalmente, nas subjetivas e artísticas.

Tais dimensões da produção do espaço social passam pela política e pela estética. Admite-se um jogo em que a população participa do espaço público de modo relativamente livre. $O$ espaço recebe o investimento de agentes e atores de modo a permitir que alguns temas, atos coletivos e performances gozem de visibilidade pública, e outros não. É essa disputa pela visualidade efetiva, como um avatar em que desembocam os desejos coletivos, que ganha maior destaque na presente análise. 
Em busca da superação de um viés que observa apenas o solapamento do espaço público pela comunicação das corporações e negócios, procura-se aqui entender os mecanismos alternativos de constituição de comportamentos e subjetividades. Para tal tarefa ser levada a cabo, parece conveniente avaliar aspectos da conjugação da performance coletiva com o uso do espaço urbano.

Foram escolhidos alguns modos de exibição coletiva para observar a disposição dos movimentos e das mensagens que se desenvolvem espacialmente na vida atual de Salvador. Para mostrar a forma como a população da capital baiana investe o desejo coletivo, servem de referência os grafites que estiveram estampados recentemente nas paredes da cidade. Essas manifestações coletivas marcam claramente o modo como a cidade é um ente estético, além de objeto da comunicação e da ação política

Essas referências concretas serão aqui discutidas do ponto de vista teórico do agenciamento coletivo. Procura-se aqui entender os modos segundo os quais as pessoas interagem e combinam suas vidas cotidianas com a experimentação e o uso espacial da arte e da comunicação. A performance coletiva e a comunicação contribuem para reconfigurar a percepção do espaço na contemporaneidade. A cidade não cessa de se transformar e se produzir através dos fluxos. Em função da circulação e da comunicação a cidade gera um poderoso espaço de exterioridade que se opõe tanto ao espaço privado quanto à interioridade do sujeito (CAIAFA, 2005). A heterogeneidade da experiência urbana dispersa focos de identidade e as recorrências dos posicionamentos políticos já familiares, introduzindo a diferença e evidenciando a produção de subjetividade.

Tendo em vista as recentes mudanças da cultura urbana de Salvador, propõe-se aqui uma discussão das transformações ocorridas no plano dos agenciamentos do desejo coletivo. Além dos mecanismos econômicos e tecnológicos que, logicamente, interferem nos fluxos da metrópole, no presente estudo, parte-se de uma concepção em que a vida cultural da cidade depende de determinadas condições de enunciação coletiva. Os estudos da história e da cultura da cidade demandam esse tipo de abordagem, já que a compreensão dos investimentos do desejo coletivo resulta do cruzamento de modelos culturais com o modo de participação da população nas atividades coletivas.

O objeto do presente trabalho consiste, em outras palavras, no estudo da disposição espacial dos fluxos e dos desejos coletivos no meio metropolitano. Ao estudar os fluxos de uma metrópole, é possível relacionar o

64 Número temático: Desenho e Educação: Cultura Visual e Cidade. A Cor das Letras - UEFS, $n$. 
processo de concentração da população em determinados eventos e lugares com o investimento dos desejos coletivos e o manejo de sua territorialidade. Através do estudo dos fluxos (ZORZO, 2011), podem ser analisadas algumas alterações pelas quais vem passando a cultura de uma metrópole como Salvador. Essa antiga capital, que se formou como sede de um dos primeiros sistemas urbanos do Brasil, mantém um papel importante no ranking nacional, em que se coloca como uma das maiores e mais dinâmicas regiões metropolitanas do país.

\section{ASPECTOS TEÓRICOS RELATIVOS AO ESTUDO DA CIDADE E DA VISUALIDADE: FLUXOS URBANOS E A AGENCIAMENTO DO DESEJO}

Muitas das possibilidades de avanço no estudo dos movimentos que confluem na cidade dependem de uma conceituação que permita conhecer as condições sócio-culturais embutidas na rede complexa de formas e diagramas que se sobrepõem no meio urbano. Um arcabouço conceitual, que tem se mostrado adequado para entender o problema da cidade e da visualidadeo, consiste em discutir o desejo coletivo e dos fluxos do ponto de vista teórico do agenciamento coletivo ${ }^{2}$.

Deleuze (1987) fez uma leitura da teoria foucaultiana ${ }^{3}$ do dispositivo de poder e amplia através do conceito de agenciamento coletivo. Essa abordagem filosófica tem um componente epistemológico interesantes para articular campos de conhecimento. Além disso, Gilles Deleuze e Foucault, ao seu tempo, dialogaram saberes com outros colegas de diversas feições disciplinares, sem prejuízo para nenhuma das partes teóricas envolvidas ${ }^{4}$.

2 Veja-se o livro de DELEUZE, Gilles. Foucault. Lisboa: Veja, 1987, uma homenagem aos estudos realizados por Michel Foucault. Deleuze faz a sua leitura da teoria foucaultiana do dispositivo de poder e assimila-o ao conceito de agenciamento coletivo.

O melhor exemplo de estudo de dispositivo está no livro Vigiar e punir, onde Foucault considerou a prisão com um dispositivo do poder na sociedade moderna disciplinar. Foucault percebeu que um diagrama se desenha em todo o campo social a partir da prisão em diversos graus de efetuação política. Ver também: FOUCAULT, Michel. Historia de la sexualidad. Vol. 1. La voluntad de saber. 2. ed. Madrid: Siglo Veinteuno de España, 1995. Ver especialmente as páginas de 99 a 125, em que o autor faz uma reflexão sobre as suas ferramentas conceituais.

4 Foucault, por exemplo, construiu uma teia de relacionamentos acadêmicos e nãoacadêmicos para elaborar a sua teoria política. Basta ver a sua conhecida obra, Microfísica do Poder, em que o filósofo-historiador dialoga com geógrafos, politicólogos e outros membros da academia e de fora dela. Como disseram as pesquisadoras brasileiras, Tere- 
O agenciamento dos fluxos dependem das mudanças da sociedade, metamorfoseiam-se com o tempo e incorporam novas significados e dispõem de novos conteúdos que se somam aos antigos saberes e técnicas. Os fluxos prestam-se às atividades sociais e integram em sua funcionalidade os padrões culturais de todos os usuários formando agenciamentos coletivos. Em outras palavras, os movimentos obedecem à lógica social que os constitui e os enreda. No caso da grafitagem nas paredes de um bairro em franca evidência na cidade, ocorre o agenciamento coletivo de enunciação.

Qualquer cidade é, visivelmente, um conjunto de formas que se acumulam e se dispõem espacialmente ao longo do tempo. Do ponto de vista semântico e sintático, são inumeráveis os signos que a urbe movimenta. Por isso, para tratar com um mínimo de acuidade os signos e analisar o acontecimento urbano, as pesquisas indicam a necessidade de selecionar eventos e tratá-los a partir de dois eixos temporais, o da simultaneidade e o da sucessão.

A reunião dos elementos nas duas temporalidades permite avaliar os fluxos da vida urbana e se aproximar do sentido alcançado pelo signo urbano. Parece conveniente, também, entender os fluxos como um dispositivo que se associa territorialmente, como é o caso da grafitagem nas paredes e muros da cidade, pois assim se observa melhor como se dispõem um conjunto de práticas que giram ao redor do impulso da coletividade e que vem desenhar uma dinâmica e intrincada configuração no interior da cidade.

Quando algo ou alguém muda de posição ou de lugar, no passar do tempo, ocorre uma operação e uma metamorfose, e o objeto do movimento é requalificado e impactado por uma determinada ação. Desse modo, pode-se observar mais de perto os caracteres que compõe o conceito de fluxo. O primeiro elemento qualitativo deriva do agenciamento coletivo (DELEUZE, 1987) que se atualiza no fluxo. O fluxo seleciona e organiza o território, como um desejo coletivo que extrai as forças do trabalho e da exibição cultural. Os movimentos e as linhas de trânsito formam redes interconectadas ineludivelmente com as redes de poder e circulação de bens. Os fluxos promovem um verdadeiro agenciamento coletivo de necessidades, afetos, demandas e desejos.

zinha e Raitz (2010), "Estudar Foucault é abrir um novo canal de pensamento, é colocar do avesso os conceitos, os pré-conceitos, a normalidade, a anormalidade, os pesos, os contrapesos, as certezas e seus contrários." Parece que este tipo de avaliação é muito pertinente aos estudos interdisciplinares.

66 Número temático: Desenho e Educação: Cultura Visual e Cidade. A Cor das Letras - UEFS, n. 
Um segundo caracter do algoritmo coletivo tem um sentido mais territorial e que adere ao espaço construído. Quer dizer, em cada empreendimento ou associação, forma-se uma colmeia de deslocamentos intermináveis que plasma um rastro sobre o espaço. Isso permite ver no agenciamento uma disposição para comunicar e criar mensagens com múltiplos significados. É o espaço social tomado pelo comportamento social segundo certas relações internas que alcançam algumas tendências predominantes.

Os atributos do agenciamento coletivo são reconfigurados e empacotados pelas práticas sociais ao longo da história, formando diversos usos coletivos $^{5}$. Segundo Baudrillard, acompanhando uma disposição para o movimento, a sociedade hoje já não vive mais no drama da circulação, mas sim "no êxtase da comunicação" 6 .

O plano de consistência dos agenciamentos é essencialmente espacial e temporal, ao qual se ligam outras dimensões culturais e informacionais. Mais do que tecnológicos, os fluxos são acima de tudo sociais. A partir dessa base sócio-cultural, se desdobram outros efeitos técnicos, como pensou o filósofo Deleuze ${ }^{7}$. O impacto dos fluxos afeta a sociedade em vários níveis de configuração. Na contemporaneidade os fluxos são desterritorializados na circulação e na reorganização do espaço. A ampliação dos fluxos concorre com expansão da produção. No capitalismo moderno, a era da quantidade e da repetição, sintomaticamente, os fluxos concorrem para o transporte e a mídia.

No presente estudo, no entanto, os fluxos que estarão sendo observados são de outra ordem, diferentes do transporte mecânico duro. Mesmo sem deixar de participar do sistema de transporte, os fluxos aqui analisados não se restringem à funcionalidade dos movimentos do capital. Isso por duas razões, sendo primeiramente que a presente abordagem assume um ponto de vista crítico e, secundariamente, por uma escolha metodológica.

Depois de tais considerações, convém situar a abordagem do objeto empírico do presente estudo. A escolha de estudar os desejos coletivos na

5 FOURQUET, François; MURARD, Lion. Los equipamientos del poder. Ciudades, territorios y equipamientos colectivos. Barcelona: Ed. Gustavo Gili, 1978.

BAUDRILLARD, Jean. El otro por si mismo. Barcelona: Editorial Anagrama, 2001.

DELEUZE, Gilles. Foucault. Lisboa: Veja. 1987, p. 65. - Dispositivo é um desenho ou composto multilinear com linhas de diferente natureza, disse Deleuze neste seu livro em homenagem a Michel Foucaul em que ampliou o escopo do dispositivo de poder para o de agenciamento coletivo. 
forma da participação popular e livre em eventos como a grafitagem das paredes da cidade por coletivos de artistasde rua. Tais ações coletivas, que serão aqui tratadas, são eventos que fogem da rotina e das atividades sistemáticas e que, por amplificar o caráter de encontro cultural, ou seja, por um efeito de multidão, alcançam um significado político ímpar.

\section{GRAFITE E AGENCIAMENTO DO OLHAR}

A atividade de artistas, grafiteiros e pichadores não pode ser reduzida à interpretação do espaço urbano a partir de elementos visuais ou traços mnemônicos e imaginários, mas deve ser inserida na complexidade da vida urbana como experiência contemporânea (LIMENA, 2001). A produção visual, ao seu modo, realiza o que Jameson (1995) denomina "mapeamento cognitivo". Esse mapeamento expressa um desejo de produzir, constituindo imagens capazes de fornecer um sentido de tempo e de lugar, a partir do qual pode-se construir não apenas um sentido de orientação para movimentação no espaço urbano, mas também formas de compreensão da realidade cultural e sociopolítica mais ampla.

Para entender o problema dos fluxos urbano em uma perspectiva interdisicplinar para enfrentar um caso concreto, agora passa-se tomar a série de obras dos artistas de rua em Salvador. Vale a pena tratar do caso da grafitagem, no bairro do Rio Vermelho, como uma referência concreta para estudar a cidade e a visualidade. O grafite é um campo de múltiplas produções espaciais na metrópole brasileira contemporânea.

Os grafites, que proliferam nos muros e paredes desse bairro proeminente de Salvador, merecem a reflexão e um acolhimento crítico por servirem exatamente para problematizar o olho e o olhar no ambiente da cidade. Cabe aqui analisar a série que está sendo permanentemente recomposta como arte da rua, por ela estar tematizando o fluxo do olho no espaço urbano. Essas figurações contemporâneas são feitas por um grupo de artistas que convivem na mesma cidade e que, sendo contemporâneos, oferecem uma diversidade de reações e proposições políticas sobre a visualidade urbana. Sob diversas condições constroem um olhar diversificado que encara o contraditório da experiência social e que ultrapassa obviamente o espaço das paredes e das ruas da cidade, proporcionando uma interação simbólica muito mais ampliada, pois as ações são levadas às mídias eletrônicas, à televisão e às redes sociais. 
Os artistas da cidade, fazem um trabalho de exibição de signos para a coletividade, colocando em discussão o olhar e a visualidade urbana. De um lado, eles exibem signos que criam uma estética contemporânea, mas, por outro, estabelecem, sob forma visual, uma fricção e um olhar crítico sobre a cidade, colocando-a em crise. A constatação de que o grafite, assim como outras formas da visualidade, pode adquirir significados diferentes, que não são univocamente definidos por um ou outro enfoque está ligada ao debate teórico sobre a multiplicidade do sentido (HAMBURGUER, 2007) da realidade.

Vejam-se casos da produção do grafite. Nos muros de Salvador há uma série de grafites que merecem a reflexão e um acolhimento analítico. A série que está sendo composta por um grupo de artistas, sob diversas condições e recursos variados, está disposta em um bairro de grande circulação, o Rio Vermelho, lugar de tensões e disputas. Não se trata de um lugar de possibilidades melodicamente ajustadas, mas um bloco espacial ocupado por elementos que se integram, forçosamente, mediante conflitos.

Por sorte, para os grafiteiros, o Rio Vermelho é um bairro de Salvador que articula diversas funções sociais e políticas. Vale lembrar que, justamente por cumprir essa função cultural, o espaço atrai a participação pública e a discussão política (NAUSSBAUMER, 2007). Bem ou mal, é um lugar onde se procura conciliar os conflitos, em que, entre outras coisas, os partidos políticos inserem seus comitês eleitorais. Artistas também abrem suas salas e fazem performances públicas.

Sob as mais diversas condições os grafiteiros constroem um olhar sobre a cidade. Os artistas fazem um trabalho de exposição para os cidadãos que usam a série de grafites e pichações como uma "janela indiscreta" da rua. De um lado artistas exibem signos que criam uma mensagem sempre renovada e efêmera, por outro o público estabelece uma interação com tal mensagem e produz uma reflexão, mesmo que fugaz. Assim, enquanto um muro branco e limpo é sinal de adequação funcional, uma parede grafitada ou pichada tem outro caráter e cria uma reação. Tal como uma série de tirinhas em quadrinhos, os muros grafitados enquadram um fluxo. Esse olhar em fluxo flui de janela a janela, ônibus a ônibus, retrovisor a retrovisor.

Com que olhos desejantes se observa a cidade? O campo do desejo do passante é ocular ou escópico. O olhar se dá ao modo cinematográfico em "traveling". As paredes de out-door estão estampadas por imagens, como as que se vê nas figuras a seguir a partir da fotos do autor do presen- 
te estudo. Se surge algo sobreposto ou pichado, o espectador capta o signo alterado e compõe uma interpretação visual rápida, conforme se vê na figura abaixo:

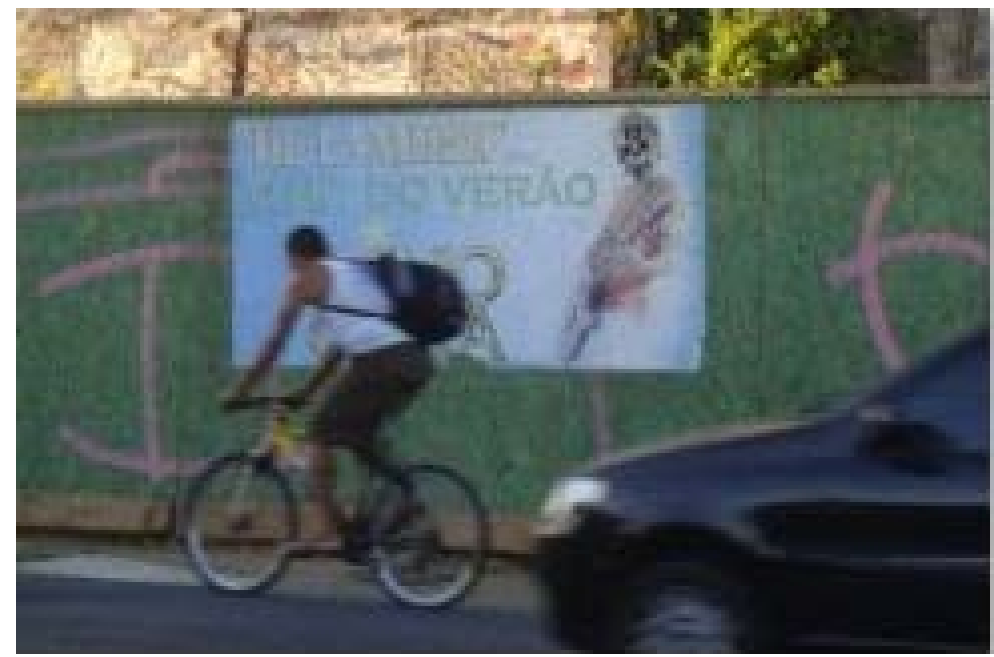

Figura 1: Cartaz com Adesivo de Caveira o Rio Vermelho Foto: Francisco Antônio Zorzo, 2012

O olhar do cidadão, que percorre as ruas da cidade, a pé, de bicicleta ou de automóvel, tende ao acionamento rápido perante a mensagem do grafite. $O$ fato de que o grafite está fixado sobre a parede, estendendo-se no plano vertical, compensa a velocidade do transeunte. A mensagem pode não ser entendida numa primeira olhadela, mas, se for o caso, com o tempo e as múltiplas passagens dos que circulam, uma percepção mais completa pode se efetuar.

O olho urbano que o grafite está procurando refletir no Rio Vermelho é coletivo e de algum modo toca toda a cidade. Os desenhos e pinturas dos rostos e dos olhos grafitados possibilitam que se perceba um coletivo em ação. Os grafiteiros muitas vezes atuam em conjunto na mesma parede ou muro, podendo fazer o trabalho no mesmo dia, ou em dias diferentes. Em coletivo eles formam um discurso sobre a cidade, nem sempre de modo ordeiro. Lançam um pensamento sobre a sociedade local e sobre o mundo contemporâneo. 
Conhecer pessoalmente alguns grafiteiros não chega a ser totalmente necessário para quem contempla a sua produção. No contexto urbano, o espectador é personagem mais anônimo que os grafiteiros. Muitos de seus depoimentos estão bem divulgados em blogues de autor e outros serviços da internet. Basta aqui lembrar, um aspecto que se destaca nesse campo de produção visual, o auto-didatismo e a auto-promoção. A conexão pode ser feita através de meios digitais, mas a rua é ainda a principal escola desses artistas. Fazem das avenidas e esquinas mostras de arte, tal como se se apresentassem em galerias do bairro.

As imagens grafitadas muitas vezes exibem olhos que se dirigem ao espectador. Uma das mensagens mais frequentes que os pichadores e grafiteiros indicam é algo assim como: "Fique ligado". Essa indicação pode estar sendo tematizada tanto na atenção a ser dada no campo do amor, como na luta pela sobrevivência ou contra a violência. Ainda no âmbito do olhar urbano e do comportamento individual, outro tema recorrente é o do encapsulamento. O indivíduo urbano na cápsula (VELLOSO, 2005) com óculos escuros e ouvindo o walkman é retratado de modo a mostrar uma independência, conforme o grafite abaixo do artista conhecido como Denis Sena.

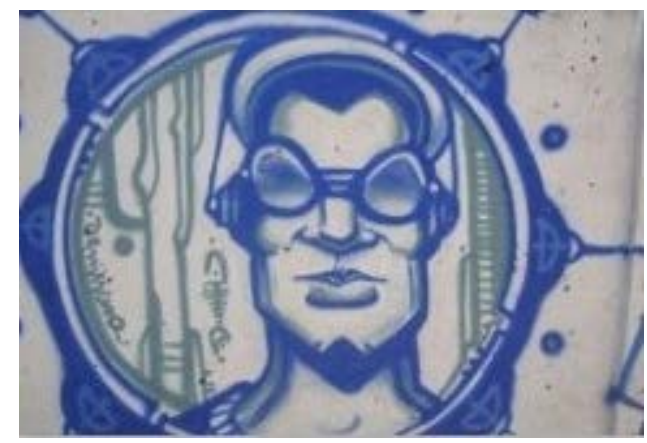

Figura 2: Grafite de Denis Sena no Rio Vermelho Foto: Francisco Antônio Zorzo, 2012

Oferecendo-se, na presente comunicação, um painel dos casos observados na grafitagem do bairro, pode-se tentar fazer uma primeira sistematização de tipos de olhar. Os olhos inscritos nos muros da cidade, que predominam no bairro do Rio Vermelho podem ser divididos em dois tipos, os de atração e os de repulsão. O olhar e a atenção implicam, em verdade, uma capacidade variável no campo do visualização. A sistematização aqui 
sugerida, entre atração e repulsão, apesar de simplificada, permite situar entre extremos a atenção e a focalização do olhar contemporâneo .
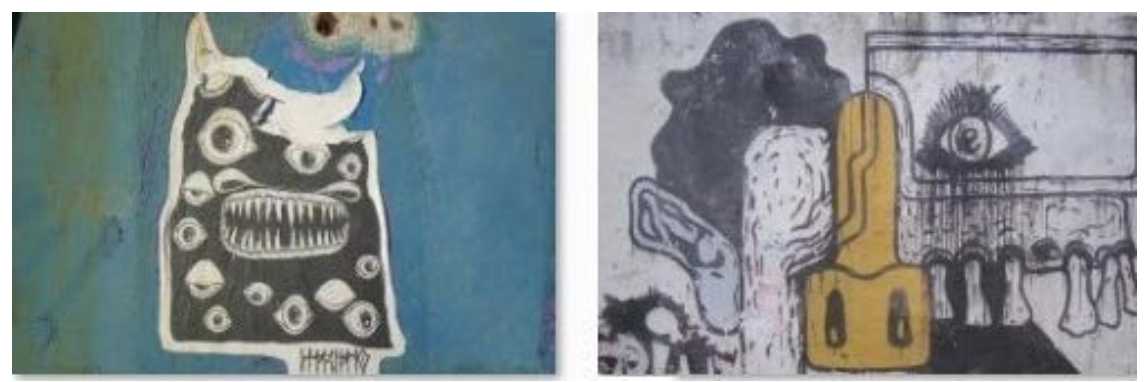

Figura 3: Adesivo e grafite no Rio Vermelho

Foto: Francisco Antônio Zorzo, 2012

Seriam olhares de atração as piscadelas, os olhares de sedução e os de contemplação. Esse tipo de troca de olhar procura acentuar, por exemplo a beleza e a graça das pupilas e cílios. O olhar repulsivo faz parte do imaginário urbano contemporâneo de evidenciar e denunciar a violência e a vigilancia (ZORZO e SAMPAIO, 2012). Os olhos que repugnam podem ser vistos através da caveira, dos olhos de monstros agressivos e dos olhares que exibem ânsias várias. Nesse segundo tipo dos olhares repulsivos entram os olhos alucinados.
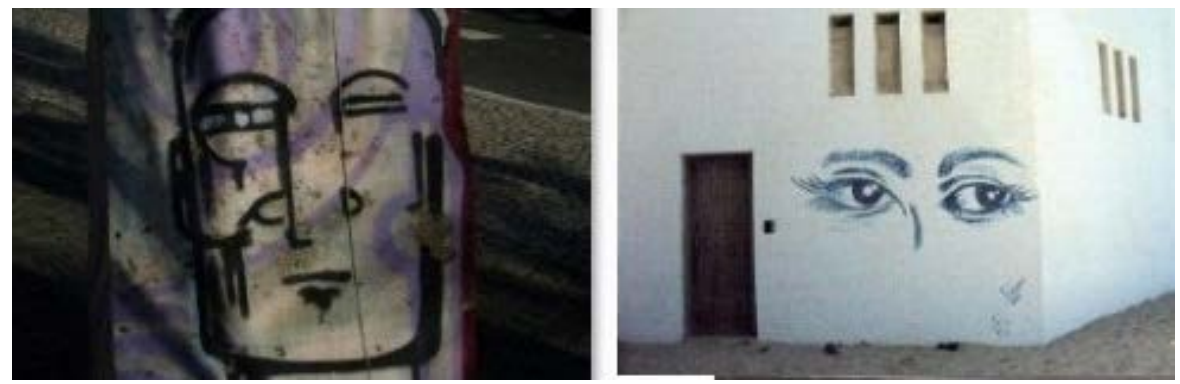

Figura 4: Dois grafites que trocam o olhar com o espectador no Rio Vermelho Foto: Francisco Antônio Zorzo, 2012

Os tipos de olhos pintados nas paredes e muros da cidade tem um efeito de fluxo e refluxo. De um lado os olhos grafados na superfície vertical da cidade vem emergir da parede para o exterior. Esse fluxo permite que o espectador se sinta observado. O punctum barthessiano (Barthes, 1984) é 72 Número temático: Desenho e Educação: Cultura Visual e Cidade. A Cor das Letras - UEFS, n. 
esse flash que se dispara para o espectador por meio do grafite. Provavelmente um grande efeito auto-figurativo do olhar frequenta a mente do grafiteiro ao propor uma imagem escópica. O refluxo, de outro lado, vem a ser a ativação do sentido derivado da recepção por parte do espectador. Esse espectador em parte é ativo, em parte passivo. O refluxo pode chegar a ser muito agressivo, como é o caso em que o grafite tende a ser vandalizado pelo espectador irritado. Conforme se vê em muitas pinturas de rua, um dos lugares mais atacados ou riscados dos grafites é justamente o olho.

Com esses exemplos que proliferam nas ruas de Salvador, ao longo do tempo, a cidade vai compondo-se segundo uma narrativa, na qual as paredes do bairro se inserem dentro campo das transformações metropolitanas, entre construções e corrosões. A história urbana do lugar ensina uma sucessão de eventos, como a expansão urbana, a verticalização e a degradação ambiental, já a histórica cultural da cidade vai exibindo outros efeitos e relatos visuais como no caso da grafitagem. As transformações espaciais e culturais são processos que também se configuram e sobrepõem enquanto sucessão de diagramas sociais e modelos de intervenção. 80 Rio Vermelho é muito bem comunicado espacialmente, em suas articulações com a vida da metrópole. Como se sabe, suas ligações se dão, principalmente, através da avenida Oceânica, da av. Vasco da Gama, da av. Garibaldi e da av. Juracy Magalhães.

De um modo geral, quando se observam as mudanças do lugar, tende-se a captar um sentido predominante relativo às condições que dominam o capital cultural da cidade. Mas não se pode cair no reducionismo, pois na mesma área da cidade proliferam inúmeras vozes em conflito. $\mathrm{O}$ modo como os movimentos grupais se manifestam varia de lugar para lugar dentro das grandes metrópoles. Uma questão que parece decisiva para Salvador é saber: quais são os significados desses fluxos e seus recorrentes impactos simbólicos? O que representam no processo de renovação quanto à inserção de cada lugar nos fluxos da cidade? Tais perguntas não podem ser respondidas de forma completa no presente comunicação, mas nem por isso devem ser deixadas de lado.

A cidade articula, nessa zona da orla, um encontro dissonante de potencialidades e realizações culturais e políticas (ZORZO, 2011). É importante constatar como, no Rio Vermelho de hoje, convergem os desejos coletivos

8

O presente trabalho foi produzido a partir de dois artigos publicados em periódico e duas mesas coordenadas nos encontros de cultura Enecult 2011 e 2012. Os artigos saíram no jornal A Tarde em janeiro e março de 2011. 
da capital baiana e como isso se traduz em mensagens visuais nas paredes do bairro. Para melhor compreender esse tema, a grafitagem é um acontecimento marcante nesse bairro da orla de Salvador. A questão é conhecer mais a fundo os fluxos que convergem para essa zona de Salvador e como se configuram tais movimentos e olhares. Deve-se partir para a observação dos fluxos dos desejos coletivos da cidade passam pela visualidade e pelo olhar. Como refletiu Merleau-Ponty (2002) sobre a arte visual, o grafite contemporâneo parece recuperar um saber pictórico "que provém do olho e dirige-se ao olho" (MERLEAU-PONTY, 2002, p. 65).

Nesse lugar de Salvador, em que os olhares se cruzam, tem ocorrido a atração irresistível de uma gama de eventos. No caso da grande celebração do bairro, que é a festa do 2 de Fevereiro, em reverência à lemanjá, o voto ou desejo do participante da festa é jogado no $\operatorname{mar}^{9}$. Na festa do Rio Vermelho o desejo flui, desse modo líquido, livre e sublime (BACHELARD, 2001). Como a festa de lemanjá ocorre defronte do oceano, o gesto de investimento do desejo lança as flores no infinito. Os votos são remetidos para as profundezas e lonjuras do sublime desejo coletivo e individual. Partindo-se da ideia de que o que flui são os desejos coletivos da capital, nesse simples ato ocorre a manifestação explícita de uma modalidade do sentimento comunitário. Esse mesmo efeito de ato livre e gratuito parece ser também encontrado nos grafites do bairro.

A pesquisa que trabalha a cidade e a visualidade, aqui relatada, se volta para a problemática das interações entre realizadores, pesquisadores e espectadores, que não se limita ao espaço urbano e atinge o campo virtual em que a imagem é registrada e torna-se objeto de reflexão. A partir de amplo material documental dos grafites, diferentes maneiras de interação na cidade. Com isso pode-se problematizar arranjos formais concretos que enfatizem seu caráter de expressão de articulações entre certos sujeitos, como os coletivos dos grafiteiros, que procuram, em alguma medida, controlar os mecanismos de construção de uma imagem de si e da sua cidade.

9 Ver: VERGER, Pierre Fatumbi. Orixás. 6. ed. Salvador: Currupio, 2009. Pierre Verger foi um grande pesquisador das festas populares de Salvador e fotografou junto à celebração anual do Rio Vermelho na década de 1950.

74 Número temático: Desenho e Educação: Cultura Visual e Cidade. A Cor das Letras - UEFS, n. 


\section{CONSIDERAÇÕES FINAIS}

A relação entre a cidade e a vida cultural modificou-se muito nas últimas décadas, o que veio exigir novas abordagens teóricas. No presente estudo tal relação foi tratada teoricamente por meio de uma abordagem interdiscipliar voltada para a cidade e visualidade. Para dar um exemplo de aplicação de tal concepção, procurou-se exibir a faceta cultural da visualidade urbana tomando-se por base o caso da inserção da grafitagem no Rio Vermelho em suas articulações com a vida corrente da metrópole.

Entre a cultura e a política deve-se observar a visualidade. Convém frisar nestas considerações de final de artigo, que podem ser encontrados, no grafite contemporáneo, elementos de uma política do cotidiano que não podem ser desprezados. Talvez não seja por acaso que a grafitagem em Salvador, específicas forças culturais confluem intensamente durante todo o ano, a cada momento de encontro coletivo. No caso das pinturas no bairro Rio Vermelho a busca de uma exibição tem um tom e uma outra forma de intensidade cultural. O bairro chama a atenção dos soteropolitanos e dos visitantes em geral, pois acolhe associações culturais, organizações políticas, além de fornecer os espaços em que inúmeros artistas fazem performances e mostras.

O que o estudo veio constatar, através da observação da grafitagem, é que os olhares estampados nos muros e paredes, de alguma maneira refletem o regime de visualidade da metrópole contemporânea. Os olhos de atração ou de repulsão grafitados em Salvador parecem participar de uma condição de visualidade que vai além dos locais concretos em que foram pintados, trazendo para perto dos cidadãos e transeúntes o tema do olho, da exibição permante, da violencia simbólica e da vigilancia na sociedade atual.

Bem se sabe, nem tudo é visualidade no estudo das cidades, mas tal móvel cultural tem servido de válvula de escape criativa, como no caso do grafite no Rio Vermelho, com suas peculiaridades de fluidez e enunciação. Para concluir, convém notar que, quando se trata dos desejos coletivos que estão sendo investidos, eles ultrapassam os anseios individuais e narcisistas de cada cidadão. Salvador é uma metrópole cujos habitantes sabem bem onde aplicar o seu desejo e o explicitam, sob modalidades específicas, em suas performances públicas.

Alguns autores reconhecidos criticam, com razão, o declínio atual do espaço público em numerosos equipamentos coletivos das metrópoles. Mas a esfera pública é campo de negociações permanente. O espaço social 
forma um campo de conflito e negociação que certamente depende de recursos, estratégias e ações dos agentes melhor posicionados, mas nenhum componente tem o poder de dominação absoluta sobre os demais. No espaço metropolitano ocorrem fluxos que tanto permitem a expansão do capitalismo, como o contrário. Foi visto aqui, através do estudo da grafitagem em Salvador, que o investimento do desejo coletivo pode produzir novos posicionamentos políticos e despertar a criação comunicativa, mas nunca a imobilidade e a homogeneidade.

A abordagem interdisciplinar aqui elaborada trabalha a cidade e a visualidade segundo a interação de realizadores, espectadores e pesquisadores. A problemática das interações entre os usuários, habitantes e estudiosos promove o fluxo urbano ao redor do agenciamento do desejo coletivo, sem se prender a um contexto limitado, de raio de irradiação acadêmico ou artístico. Basta ver a bibliografia de apoio do presente estudo, para perceber que o pensamento sobre a cidade circula entre diversos campos, como a antropologia e o urbanismo, passando pela semiologia e a comunicação. Percebe-se que com uma abordagem que assume uma certa transversalidade teórica e prática não se restringe ao espaço urbano e arquitetônico concreto, de modo que o grafite torna-se um objeto de reflexão mais abrangente e dinâmico.

\section{REFERÊNCIAS}

BACHELARD, Gaston. A poética do espaço. São Paulo: Martins Fontes, 1988.

BARTHES, Roland. A câmara clara: nota sobre a fotografia. Rio de Janeiro: Nova Fronteira, 1984.

BAUDRILLARD, Jean. El otro por si mismo. Barcelona: Anagrama, 2001.

CAIAFA, Janice. Comunicaçao e diferença nas cidades. Lugar Comum, n. 18, 2005.

DELEUZE, Gilles. Foucault. Lisboa: Veja, 1987.

FOUCAULT, Michel. Historia de la sexualidad. Vol. 1. La voluntad de saber. 2. ed. Madrid: Siglo Veinteuno de España, 1995.

FOURQUET, François; MURARD, Lion. Los equipamientos del poder. Ciudades, territorios y equipamientos colectivos. Barcelona: Ed. Gustavo Gili, 1978.

HAMBURGER, Esther. Violência e pobreza no cinema brasileiro recente: reflexões sobre a ideia de espetáculo. Revista Novos Estudos CEBRAP, n. 78, 2007.

JAMESON, Fredric. Espaço e imagem. Teoria do pós-modernismo e outros ensaios. Rio de Janeiro, Ed. UFRJ, 1995. 
LIMENA, Maria Margarida. Cidades complexas no século XXI - ciência, técnica e arte. Revista São Paulo em Perspectiva, v. 15, n. 3, 2001.

MERLEAU-PONTY, Maurice. O olho e o espírito. Lisboa: Veja, 2002.

NAUSSBAUMER, Gisele Marchiori. (Org.). Teorias e políticas da cultura: visões multidisciplinares. Salvador: Edufba, 2007.

FERREIRINHA, Isabella Maria nunes; RAITZ, Tânia Regina. As relações de poder em Michel Foucault: reflexões teóricas. Revista Admistração Pública. Rio de Janeiro, v. 44, n. 2, 2010.

VERGER, Pierre Fatumbi. Orixás. 6. ed. Salvador: Currupio, 2009.

VELLOSO, Rita. De interfaces tecnológicas e rascunhos de experiências. Kriterion: Revista de Filosofia, v. 46, n. 112, 2005.

ZORZO, Francisco Antônio. Ferrovia e rede urbana na Bahia. Feira de Santana: UEFS, 2001.

ZORZO, Francisco Antônio. Os desejos coletivos e os fluxos da metrópole. In: Anais do VII ENECULT - Encontro de Estudos Multidisciplinares em Cultura. Salvador: UFBA, 2011.

ZORZO, Francisco Antônio; SAMPAIO, Eledison. Vigilância contemporânea: o emprego do vídeo como violência na cidade. In: Anais do VII ENECULT - Encontro de Estudos Multidisciplinares em Cultura. Salvador: UFBA, 2012. 
